\title{
Focus of Cellular Alteration
}

National Cancer Institute

\section{Source}

National Cancer Institute. Focus of Cellular Alteration. NCI Thesaurus. Code C120882.

A group of cell that show altered characteristics in comparison to normal cell types and are confined to a specific area of the sample. 